\title{
On the Expression of Chinese Traditional Aesthetics in Chen Man’s Photography Works
}

\author{
DAI Xiao-ling, KAN Qing (Corresponding Author) \\ School of Fine Arts, Nanjing Normal University, Nanjing, China
}

\begin{abstract}
As a contemporary fashion photographer and international visual artist, Chen Man has become one of the most influential photographers with heravant-garde in sights and creative personalities. Her works not only show a strong Chinese style, but also show the charm of modern fashion. This paper starts with the Chinese elements in Chen Man's photography works, analyzes the application of Chinese traditional aesthetics theory in Chen Man's photography, explores the expressions and characteristics of the collision between Chinese tradition and Western modernity in her works, and hopes to give inspiration for the development of current Chinese fashion photography.
\end{abstract}

Keywords: Chen Man, photography, tradition, modern

\section{The Photographer Chen Man in the Eyes of Westerners}

From painters to photographers, designers, directors, to today's international visual artists, Chen Man's role is constantly changing, and the photography she creates is unique in the photography world. Through her magical hands, many classic characters and images filled with beauty and connotation were generated. Chen Man's style cannot be defined by an accurate word, but the collision and coordination between the traditional and avant-garde elements is vividly displayed in her works, and she has thus become a pioneer in the development and innovation of modern visual art.

Chen Man records and passes on Chinese faces and culture from a fashion perspective, opening a window for understanding the Chinese culture for the world, and she becomes a prominentChinese brand on the international stage. As The Business of Fashion Divia Harilela evaluates Chen Man's works which presents to the audience are: "As an artist and fashion photographer, Chen Man has built up an oeuvre best known for its high-impact, unapologetic transgression of China's cultural boundaries”. ${ }^{1}$ With the help of amazing painting skills, she combines Chinese philosophical thoughts with her own thoughts and highlights rich cultural connotations in the form of fantasy-filled visual works. As the promoter of Eastern and Western cultures, the New York Times Weekly called Chen Man “China’s Anne Leibovitz”.2 Such an evaluation is an affirmation of Chen Man's interpretation of herself through photography.

DAI Xiao-ling, under postgraduate, postgraduate, School of Fine Arts, Nanjing Normal University.

KAN Qing (Corresponding Author), lecturer, Ph.D. candidate, School of Fine Arts, Nanjing Normal University, Nanjing.

${ }^{1}$ Divia Harilela. Chen Man's Visual Revolution [Online]. Retrieved from:

https://www.businessoffashion.com/articles/creative-class/chen-mans-visual-revolution

2 Valeriya Safronova. Meet Chen Man, the “ChineseAnnie Leibovitz” [Online]. Retrieved from:

https://www.nytimes.com/2017/05/10/fashion/meet-chen-man-the-chinese-annie-leibovitz.html (May10, 2017). 
As we all know, beautiful photos are easy to obtain, but the fleeting visual enjoyment cannot constantly keep viewers in mind. The iDmagazine once commented Chen Man's works: "Innovating the way China and the world look at beauty" (Natascha, 2013, p. 10). The reason why Chen Man is recognized at home and abroad is that every detail of her work reflects cultural connotation and the appropriate blend of modern fashion. Chen Man's works are full of contradictions, which means the conflict between modernity and tradition, and characters, but various contradictions are in rhythmic harmony.

\section{The Construction of Chinese Style in Chen Man's Works}

\section{Inspiration Sources}

As a native 80s was born in Beijing Hutong, Chen Man's work is inspired by her life. It is not difficult to find that many of her childhood experiences have become shooting scenes: riding a bicycle in front of Tiananmen Square; carrying watermelons and playing in the alley; playing mahjong in the courtyard. Based on a modern perspective, Chen Man reinterprets the familiar life scenes of the 1980s since the reform and opening up, which not only evokes the memories of that generation, but also shows the current rapid development of China.

Inspiration is the source of artistic creation. Many scholars have different opinions on inspirationat home and abroad. In ancient China, the writer Lu Ji firstly proposed the inspiration for artistic creation: "If artist feels an interesting point, they cannot stop it, and when it disappears, the artist cannot stop it. when it hides, like a suddenly disappearing shadow, but when it reveals, just like a suddenly appearing sound” (Zhang, 2002, p. 241). Here the interesting point refers to inspiration, is the moment when the artist's heart and things meet and instantly arises. Therefore, the acquisition of artistic inspiration is mainly based on the artist's sensibility and rational balance between things.

In her work'contemporary China' series, Du Juan, wearing a Chinese classic red dress, leans against the flagpole of the five-star red flag on the background of the Shanghai's landmark-The Oriental Pearl Tower. In the picture, the popular "weaveand stop" hairstyle in the early 1980s makes Du Juanmore powerful. In addition, Du Juanwho wears the safflower is holding the Chinese national flower-Peony and standing in front of the famous tourist attraction-Tiananmen Square. The same shootingabout Du Juan, one is in Shanghai, the other one is Beijing. Chen Man once compared Shanghai to a woman and Beijing to a man. However, through different interpretations of different Chinese representative landmarks, it isdeeply impressed with the brand of china.

In addition, "Funky Great Wall” series which are shot in the Great Wall have oriental characteristics. Dressed in a punk style, Lyu Yan is carrying with 80's special trends: dual-card recorders, ancient mobile phones, airplane wigs, etc. The objects of the sense of history are renewedly interpreted by her, delivering a modern atmosphere, and the historic Great Wall has changed instantly. It has become a modern and fashionable place. From these new and familiar scenes, the audience can discover the epitome of daily life, and at the same time the picture leaves room for thinking.

Although Chen Man uses life as a source of inspiration, every detail in the picture highlights the meaning of Chinese culture. Therefore, through her works, the Chinese people and the world's views and perceptions of China have been reshaped. As the British art theorist Robin Collingwood once said, the emergence of art works is controlled by the artist himself, which is called the controllable power of inspiration. Therefore, for excellent works of art, the re-creation of the artist's inspiration is the most crucial. 


\section{The Symbolicuse in Chinese Traditional Culture}

The elements of Chinese traditional culture can be seen everywhere in Chen Man's works. Totem, Buddhism, Taoism and so on which prompte her works to achieve the integration of Chinese tradition and modernity and reveal the unique Chinese with modern characteristics. For Chen Man, Chinese philosophy means software, while Western culture means hardware. ${ }^{3}$ When the American Budweiser beer meet Chinese Taiji, which shows the Eastern woman who came from the 1950s to the presentis in one single gesture or word to present the process of Budweiser's production as the time going on. The perfect combination of learning stationery brandcalled Chen Guang and the national quintessence of Peking Opera, which represents the diversification and inclusiveness of Chinese traditional culture.

The "Five Elements" series is one of Chen Man's masterpieces. In ancient China, the five material relationships of gold, wood, water and fire were used to describe the relationship among the world. The destruction of the natural environment seems to be a personal act, but it will exert tremendous pressure on the entire ecology and the Earth system. In this series, Chen Man creates a golden woman who is overwhelmed by explosive metal products; a wooden woman who is bound by desertification and vegetation destruction; a water woman that is placed on the ocean but is roasted by the sun; aninjuredwoman comes from the battlefield which are filled with smoke and fire; a dirt woman swallowed up by the white garbage and break through the soil from sand-coveredair.In addition, the scenes of ordinary people can be seenrespectively on the right of in each group of these five women. The ordinary people are laughing happily. And the whole pictures reveal a mood and state of mix. This set of photographs is a depiction of nature and a disclosure of human's greedy desire.

With the rapid development of modern China, The destruction of the ecological environment and the deterioration of resources are problems need to be solved. However, Chen Man has used the symbolic use of Chinese traditional culture to alert people to the relationship between man and nature. Chinese traditional culture is the result of the accumulation of the Chinese history and the spiritual wealth accumulated through long-term social practice. With the time goes on, Chinese traditional culture has always had rich connotations and strong vitality. In recent years, the traditional Chinese culture is widely used in photography. It not only promotes the Chinese cultural connotation, but also promotes the collision and blending of Chinese culture and world culture,which makes China stands in the world forest with a new look and posture.

\section{From Record to Create}

When Chinese photographers speak highly of the documentary function of photography, Chen Man took the lead in using post-production. The use of a large number of software such as Photoshop, Maya, 3Dmax and so on, which has caused extensive discussion in a short period of time. The photos she photographed for Vision magazines howed incredible creativity and gave unlimited imagination to the viewer. From the initial controversy to the gradual acceptance and recognition, Chen Man has turned photography from a recording tool to a creative tool with unlimited possibilities.

The birth of photography is inseparable from the advancement of technology. The techniques carry with thoughts, which means ingenuity. Although art and technology seem to have a distinction between elegance and

3 Satsuki Miyanishi, Yuta Sakuraba. Chen Man: A Futurist in the 21st Century [Online]. Retrieved from: http://www.shift.jp.org/en/archives/2012/03/chen_man.html (14 March, 2012). 
vulgarity, the two are like the relationship between the warp and the latitude on the earth. They seem to operate independently, but they are always inseparable. Without technology, art seems to be struggling. In ancient China, Zhuangzi said that "when a certain skill reaches its peak, it will be exposed to the 'Tao', that is, the law of heaven and earth” (Zhang, 2010, p. 398), which not only emphasizes the importance of technology, but also reveals the technology should be combined with art and therefore achieve the state whichmeet people's aesthetic enjoyment.

In recent years, Chen Man has also incorporated artificial intelligence into her own artistic creation, bringing new thoughts about human and technology in the new era. For her, technology and art are in a state of balance, what she cares more is the emotion and meaning brought by the picture, rather than thinking which technological meansare better. Due to the proficient skill inmodern technology, the "Four Great Kings" series reflects the threat to the natural environment caused by human behaviors under the rapid development of a modern society. The "Eight Immortals Crossing the Sea” series combines traditional Chinese mythology with ordinary people and modern fashion, showing the ordinary people's silent efforts and hard work for the development of society. As Chen Man believes, a work is made up of many factors, each of which is importantrelevantly and alsocan be said to be irrelevant.

The relationship between technology and art is like the relationship between virtual and real in Chinese art. As Chen Man himself has said, beauty is divided into two types: real and virtual. If a piece of art does not motivate the audience to imagine, then the artwork has no meaning. In other words, art should be combined with reality and virtuality. Fan Xiwen, a literary theorist in the Southern Song Dynasty, once said: "Inliterature creation, if you only write empty and lyric words, you will feel monotonous. If you only depicts existing scenery and thus it will lack of vitality. Only with tangible scenery states to express your thoughts and feelings, which may achieve meaningful artistconception” (Zong, 2009, p. 8). That means we can achieve inner spirit by things in nature, which acquires the balance between virtuality and reality and thus creating a profound and energetic art masterpiece. Just as the painter Zhang Wei of the Tang Dynasty advocated that art comes from the reality, however, before this reality becomes artistic beauty, it must be reshaped and recreated through artist's subjective emotions and thoughts. So the artistic creation is based on the blending of nature and the artist's emotions, thus creating a fascinating artistic conception.

\section{The Fusion of Avant-garde and Tradition}

\section{The Image Construction of Contemporary Chinese Aesthetics}

In the context of a technologically advanced globalization, aesthetics is not only a phenomenon, but an aesthetic trend in the form of visual images, and profoundly affects the cultural consciousness and values of contemporary people. The context of globalization has opened up people's perceptions of culture. But it is undeniable that beauty is the pursuit of many artists. The artist's understanding of beauty directly affects the creation of his works of art. As Chinese esthetician Zong Baihua once said: "Art is creating beauty. This beauty is not produced in the process of artist's creation, but the moment the reader feels moved” (Zong, 2009, p. 182). In other words, the artist's aesthetic embodiment does not require the artist's verbal description because all sentiments are showingin the works of art.

The influence of aesthetic conceptsin Chinese traditional culture on Chen Man's works is profound. From the perspective of the development of Chinese aesthetic history, the beauty of art is closely related to the morality 
and righteousness of Confucianism. Therefore, the reason why the emphasis on artistic conception in Chinese art is that functions as tool to improve the realm of people personality. In Chen Man's view, when the materiality of modern life meets people's needs for life, people are eager to have an interaction with emotions and traditions that they have experienced. For example, Chinese aesthetician Li Zehou divides the aesthetic form into: nice-looking and pleasant to hear; express the reflection of social phenomenon and stimulate people to think; inspirepeople's spirits and affect people's values.Chen Man seems to obey Chinese traditional culture, but actually she is an art rebel. On the basis of using traditional visual elements, techniques and ideas, she breaks through the spiritual meaning of traditional culture and achieves the status which means body and mind as a whole. If we say Chinese traditional culture prefer to be more aesthetic, while the West is more logical and promotes a scientific spirit. Under the background of the full diversity of Chinese and Western cultures, the visual language of Western modernization has brought new development space for traditional cultural aesthetics. The photographic works she created are full of creativityand vitality. Through the digital technology, the rich visual experience through the picture makes the viewers have a deeper experience and understanding of the aesthetic ideals in Chinese traditional culture, and at the same time it promotes contemporary Chinese culture and it will become more diverse and inclusive.

\section{The Image-building of Chinese Modern Women}

In Chinese traditional culture, women are a special group. They are the carrier of beauty and also reflect the changes in social development. The aesthetics of traditional Chinese female images are mainly determined by the male-dominated social status. However, as the times going on, the aesthetic image of the female is changing from the traditional to the modern. Different from the deep-rooted thoughts "men outside the home, women inside", the female image nowadays has become a beautiful landscape in aesthetics.

Women are very important subjects in Chen Man's works. Under the lens of Chen Man, women can completely release themselves and no longer serve as the vassal of men, showing the most real aspect. In Chen Man's early one-inch headshot series, the freckles on the faces of characters were preserved, aiming to show the most authentic personality. She has also blackened Asian faces and shoots a variety of single eyelid women, breaking the traditional female aesthetic concept of white skin and double eyelids. Although making up, wearing sexy underwear, tattoos and so on are the characteristics of women in this era, the charm of visual art lies in the deep imprint of audiences, thus becoming the characteristics of the times. In 2010, Li Bingbing was selected as the best cover in the world with her red lips and retro red hood.

Many women subverted their own perceptions and explored themselves different from their own original perceptions through her lens. It not only reflects the traditional Chinese female image, but also expresses the mystery and aggression of modern women. In the fashion circle of the West in the 1940s, the concept of "non-sexism" prevailed, and it was hoped that the social profile would be expressed through diversified expression. The women in Chen Man's works can also show a lot of strong masculinity. For example, Fan Bingbing played Che Guevara, Superman, Bruce Lee, Elvis, etc., successfully created the title of "Fan Ye". Every time Chen Man's the experience of cooperating with female stars brings brand new images ofthe feminine charmin different levels, the original single female character has been completely subverted. The line between women and men is not clear and women are liberated and free through Chen Man. 


\section{Conclusion}

Chen Man demonstrates her own understandings about Chinese traditional culture and the problems of modern society through her lens full of infinite possibilities, prompting people to think about the current social development status and Chinese traditional culture. She dedicates to the fusion between modern fashion photography and Eastern and Western cultures. Chen Manhas brought new hope and endless possibilities to Chinese fashion photography and Chinese traditional culture. At the same time, modern visual languages she use make Chinese traditional aesthetics and modern female images more vivid and vigorous.

\section{References}

Divia, H. (n.d.). Chen Man's visual revolution [Online]. Retrieved from: https://www.businessoffashion.com/articles/creative-class/chen-mans-visual-revolution.

Natascha, R.-T. (2013). The new Shanghai Xiaojie: Chinese fashion identities. 2nd International Non-Western Fashion Conference, London 21-22 November 2013.

Satsuki, M., \& Yuta, S. (2012). Chen Man: A futurist in the 21st century [Online]. Retrieved from: http://www.shift.jp.org/en/archives/2012/03/chen_man.html (14 March, 2012).

Valeriya, S. (2017). Meet Chen Man, the "Chinese Annie Leibovitz" [Online]. Retrieved from: https://www.nytimes.com/2017/05/10/fashion/meet-chen-man-the-chinese-annie-leibovitz.html (May10, 2017).

Zhang, S. K. (2002). Lyrics set interpration. Beijing: Renming Literature Press.

Zong, H. B. (2009). Zong Huabai aesthetics and his Wen Xuan. Henan: Henan Wenyi Press. 